\title{
Correction to: Bioprospecting of Microorganisms for Biofuel Production
}

\author{
Sonali Bhardwaj, Sachin Kumar, and Richa Arora
}

\section{Correction to:}

Chapter 2 in: A. N. Yadav et al. (eds.),

Biofuels Production - Sustainability and Advances

in Microbial Bioresources,

\section{Biofuel and Biorefinery Technologies 11,}

https://doi.org/10.1007/978-3-030-53933-7_2

In the original version of the chapter, the following correction has been incorporated:

The authors' names have been changed from "Richa Arora Sonali and Sachin Kumar" to "Sonali Bhardwaj, Sachin Kumar and Richa Arora". 